\title{
Methyl Formate: an Experimental and Kinetic Study of its Oxidation at High-Pressure
}

\author{
Lorena Marrodán, Ángela Millera, Rafael Bilbao, Ma Ujué Alzueta \\ Grupo de Procesos Termoquímicos (GPT) \\ Instituto de Investigación en Ingeniería de Aragón (I3A). \\ Universidad de Zaragoza, Mariano Esquillor s/n, 50018, Zaragoza, Spain. \\ Tel. +34-876555451, Fax+34-976761879, e-mail: marrodan@unizar.es
}

\begin{abstract}
An experimental and kinetic modeling study of the influence of pressure on the oxidation of methyl formate (MF) has been performed in the 1-60 bar pressure range. The influence of stoichiometry, temperature, pressure and presence of NO on the conversion of MF, and on the formation of the main products, has been analyzed.
\end{abstract}

\section{Introduction}

Nowadays, transport is one of the main responsible of the emission to the atmosphere of different pollutants (nitrogen oxides, sulfur oxides, carbon dioxide and particulate matter, mainly), with a variety of potential effects on environment and/or human health.

Despite of their high fuel efficiency and lower emissions of hydrocarbons and $\mathrm{CO}$, diesel engines suffer from high emissions of particulate matter and $\mathrm{NO}_{\mathrm{x}}$. Reduction of both emissions at the same time still remains as one of the major tasks in these engines development due to the increasing concern on environmental protection.

A prospective solution to this problem is to use oxygenated alternative fuels or to add the oxygenated compounds to the diesel fuels to provide more oxygen during the oxidation, without significant changes in the combustion chamber. One of these compounds is methyl formate, MF $\left(\mathrm{CH}_{3} \mathrm{OCHO}\right)$.

Furthermore, MF is an important intermediate or final product during the oxidation of other promising diesel fuel additives, such as dimethoxymethane (DMM) or dimethylether (DME) in the presence of $\mathrm{NO}_{\mathrm{x}}[1]$.

MF is the simplest member of the ester family, the fundamental constituent of biodiesel. Due to the volatile nature of the esters, the presence of MF in the atmosphere is a reality. Therefore, many studies about the MF decomposition in the atmosphere have been reported in the literature (e.g. [2]). However, from both experimental and kinetic modeling points of view, only a few studies at high temperatures and, even less, at pressure can be mentioned.

\section{Scope and objectives}

In this context, the present work aims to extend the experimental data from flow reactor results on MF oxidation at pressures higher than atmospheric, since those results will be helpful for engine applications. Furthermore, the interaction between MF and NO is also analyzed by adding a given amount of NO to the reacting system. Specifically, the oxidation of MF has been investigated under flow reactor conditions, at different pressures (atmospheric, 20, 40 and $60 \mathrm{bar}$ ), in the 573-1073 K temperature interval, from reducing to very fuellean conditions, both in the absence and in the presence of NO. Additionally, the experimental data will be interpreted in terms of a detailed kinetic modeling study based on the MF mechanism subset by Dooley et al. [3], updated by Alzueta et al. [4] and revised and completed in the present work. Model calculations have been performed using Senkin which runs in conjunction with Chemkin-II library, considering pressure and temperature constant in the reaction zone, which has been tested to be a fairly good assumption.

\section{Experimental}

This work includes an experimental study on MF oxidation in the presence and in the absence of NO. Figure 1 shows the experimental installation used to perform the different oxidation experiments.

The installation basically consists of a feeding system (gas/liquid), a reaction system and a gas analysis system.

MF liquid is supplied using a CEM (Controlled Evaporation Mixer), which evaporates the liquid 
and then it is mixed with $\mathrm{N}_{2}$ as carrier gas. All gases are supplied from cylinders through mass flow controllers.

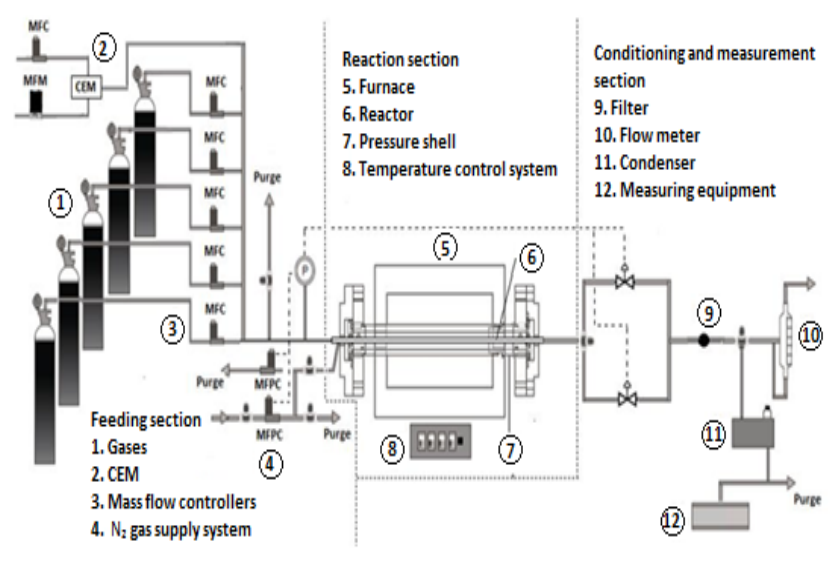

Fig. 1. Diagram of the high-pressure gas-phase installation.

The reaction system consists of a quartz reactor enclosed in a stainless steel tube that acts as a pressure shell. A pressure control system, consisting of two thermal mass flow pressure controllers, automatically delivers $\mathrm{N}_{2}$ to the shell-side of the reactor to obtain a pressure similar to that inside the reactor, avoiding the reactor breaking.

The outlet gas composition is measured using a micro gas chromatograph equipped with TCD detectors, able to detect MF, $\mathrm{CO}, \mathrm{CO}_{2}, \mathrm{H}_{2}, \mathrm{CH}_{3} \mathrm{OH}$, $\mathrm{CH}_{2} \mathrm{O}$, and hydrocarbons $\left(\mathrm{CH}_{4}, \mathrm{C}_{2} \mathrm{H}_{2}, \mathrm{C}_{2} \mathrm{H}_{4}, \mathrm{C}_{2} \mathrm{H}_{6}\right)$; a continuos IR analyzer to measure the $\mathrm{NO}$ concentration; and a Fourier Transform Infrared (FTIR) spectrometer to check the formation of some nitrogen compounds such as $\mathrm{NO}_{2}, \mathrm{HCN}$ or $\mathrm{NH}_{3}$.

\section{Conclusions}

Results indicate an important influence of pressure, with the MF conversion shifted to lower temperatures when pressure is raised from atmospheric conditions to 20 bar and higher ones. The formation of $\mathrm{CO}_{2}$ is clearly favored at high pressures, whereas other products (such as $\mathrm{CH}_{4}$ or $\mathrm{H}_{2}$ ) are hardly formed.

Moreover, at high pressures, the reaction pathways are slightly more complex compared to atmospheric conditions due to the formation of some radicals, such as $\mathrm{CH}_{2} \mathrm{OCHO}$ and $\mathrm{CH}_{3} \mathrm{OCO}$. In the presence of $\mathrm{NO}$, results indicate no net reduction of $\mathrm{NO}_{\mathrm{x}}$, although under high pressure conditions the interconversion $\mathrm{NO}-\mathrm{NO}_{2}$ becomes very important.

\section{Acknowledgements}

The authors express their gratitude to the Aragón Government (GPT group) and to MINECO and FEDER (Project CTQ2012-34423), for financial support.

\section{REFERENCES}

[1]. DOOLEY, S., BURKE, M.P., CHAOS, M., STEIN, Y., DRYER, F.L., ZHUKOV, V.P., FINCH, O., SIMMIE, J.M., and CURRAN, H.J. Methyl formate oxidation: Speciation data, laminar burning velocities, ignition delay times, and a validated chemical kinetic model. International Journal of Chemical Kinetics. 2010, 42(9), 527-549.

[2]. GOOD, D.A, and FRANCISCO, J.S. Tropospheric oxidation mechanism of dimethyl ether and methyl formate. Journal of Physical Chemistry A. 2000, 104(6), 1171-1185.

[3]. DOOLEY, S., DRYER, F.L., YANG, B., WANG, J., COOL, T.A., KASPER, T., and HANSEN, N. An experimental and kinetic modelin study of methyl formate low-pressure flames. Combustion and Flame. 2011, 158(4), 732-741.

[4]. ALZUETA, M.U., ARANDA, V., MONGE, F., MILLERA, A., and BILBAO, R. Oxidation of methyl formate and its interaction with nitric oxide. Combustion and Flame. 2013, 160(5), 853-860. 